\title{
Trattato delle Cefalee (Treatise on Headaches)
}

\author{
V. Gallai, L.A. Pini \\ Centro Scientifico Editore \\ Turin, ISBN 88-7640-616-6
}

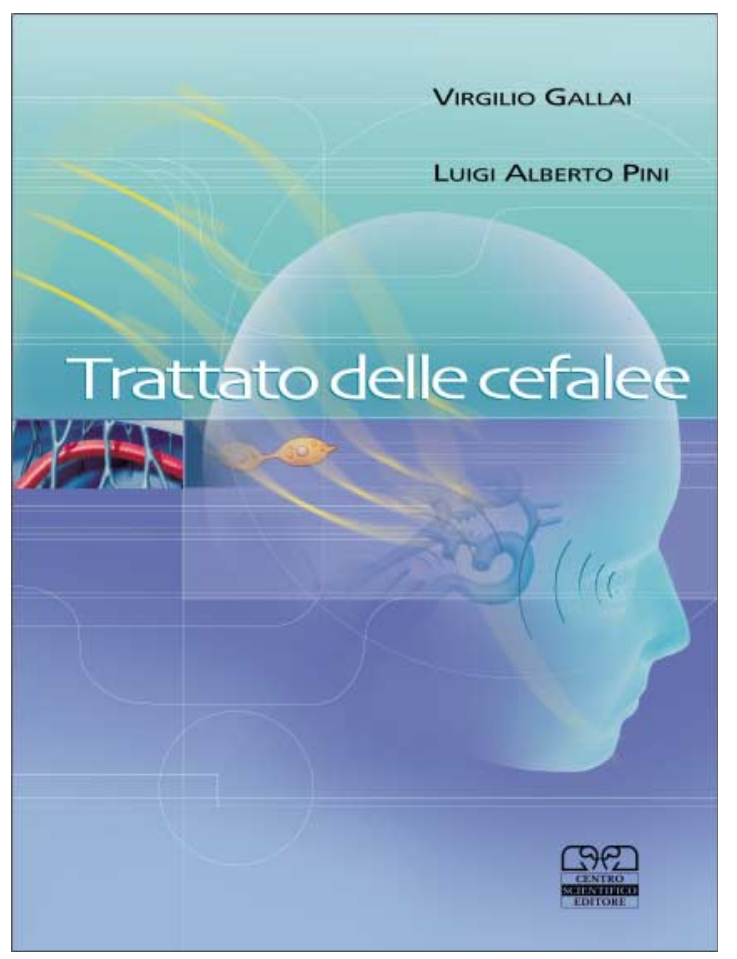

Even though the scientific study of headache in Italy began in the 1950s, only books written in English and then translated into Italian have been available on the market in the past few years. Trattato delle Cefalee, the first Italian volume to provide a complete and exhaustive overview of all headache disorders, targets both general practitioners and specialists interested in this topic. With this publication, the editors have responded to an increasing demand for an exclusive source of information in this complex field of medicine where conflicting data exist. The book provides a detailed and attentive description of the clinical features of both primary and secondary headache disorders, emphasizing the need for a correct diagnosis, which is an essential prerequisite for effective therapeutic intervention.

Symptomatic therapy and preventive treatment of the primary headache disorders are dealt with clearly by the coauthors, and a notable effort was made in presenting the most up-to-date approaches and the most recent acquisitions, without neglecting non-pharmacological therapies.

Although the volume is focused, above all, on the clinical and therapeutic aspects concerning headache disorders, it also includes the more recent pathogenetic and neurophysiological hypotheses, exemplifying, in essential but complete conceptual schemes, the most current information on this matter and suggesting the problems that are still unresolved and need to be explored.

The book concludes by reproducing the Diagnostic and Therapeutic Guidelines for Migraine and Cluster Headache written, by the Italian Society for the Study Headaches. The guidelines, prepared by a special ad hoc committee composed of more than 50 prominent Italian researchers in the field of headache, offers the practitioner and specialist a helpful aid in daily activities. Lastly, the analytical index is detailed, making it easy to find arguments of interest.

This book is particularly suitable for doctors who study or would like to study and treat headaches, both in and out of the hospital setting.

$$
\begin{array}{r}
\text { M. Fanciullacci } \\
\text { President of the Italian } \\
\text { Headache Society } \\
\text { clo Headache Centre } \\
\text { Viale Pieraccini 18, I-50129 Florence, Italy } \\
\text { Tel.: +39-055-4296512 } \\
\text { Fax: }+39-055-430731
\end{array}
$$

